\title{
Palmitate induces H9c2 cell apoptosis by increasing reactive oxygen species generation and activation of the ERK1/2 signaling pathway
}

\author{
CHUAN-DONG WEI ${ }^{1,2}$, YAN LI ${ }^{1}$, HONG-YUN ZHENG $^{1}$, YONG-QING TONG ${ }^{1}$ and WEN DAI $^{1}$ \\ ${ }^{1}$ Department of Clinical Laboratory, Renmin Hospital of Wuhan University, Hubai 430060; ${ }^{2}$ Department of \\ Clinical Laboratory, Affiliated Hospital of You Jiang Medical University for Nationalities, Guangxi 533000, P.R. China
}

Received September 21, 2012; Accepted January 3, 2013

DOI: $10.3892 / \mathrm{mmr} .2013 .1276$

\begin{abstract}
Cardiac myocytes undergo apoptosis under conditions of high free fatty acid concentrations, including palmitate, which is implicated in lipotoxic cardiomyopathy. However, the underlying mechanisms remain unknown. The aim of the present study was to understand the role of reactive oxygen species (ROS) production and the extracellular signal-regulated kinase 1/2 (ERK1/2) signaling pathway in palmitate-induced apoptosis in $\mathrm{H} 9 \mathrm{c} 2$ cells. $\mathrm{H} 9 \mathrm{c} 2$ cells were exposed to palmitate for $12 \mathrm{~h}$. The effect on the cell viability of H9c2 cells was evaluated using the 3-(4,5-dimethylthiazol-2-yl)-2,5-diphenyltetrazolium bromide (MTT) assay and cell apoptosis was determined by Hoechst 33342 staining. Levels of intracellular ROS were determined using a peroxide-sensitive fluorescent probe, 2',7'-dichlorofluorescein diacetate. Protein expression was measured by western blot analysis. Following treatment with palmitate for $12 \mathrm{~h}, \mathrm{H} 9 \mathrm{c} 2$ cells apoptosis was demonstrated as increased brightly condensed chromatin or unclear fragments by staining with Hoechst 33342, which was associated with increasing levels of active caspase- 3 and cleaved poly (ADP-ribose) polymerase (PARP). In this model of treatment with palmitate, $\mathrm{H} 9 \mathrm{c} 2$ cell apoptosis correlated with increased levels of p53 and Bax expression and reduced levels of Bcl-2 expression. Palmitate-induced apoptosis was observed to increase levels of intracellular ROS production and p-ERK1/2 and decrease p-Akt significantly. Consistent with these results, palmitate-induced apoptosis was attenuated by the ERK1/2 inhibitor, U0126, through partial reduction of intracellular ROS generation. Collectively, these results indicate that palmitate-induced apoptosis in H9c2 cells is mediated by activation of the ERK1/2 signaling pathway and increased ROS generation.
\end{abstract}

Correspondence to: Professor Yan Li, Department of Clinical Laboratory, Renmin Hospital of Wuhan University, 99 Ziyang Road, Hubei 430060, P.R. China

E-mail: yanlitf@yahoo.com.cn

Key words: $\mathrm{H} 9 \mathrm{c} 2$ cells, palmitate, apoptosis, reactive oxygen species, ERK1/2

\section{Introduction}

Saturated fatty acids, including palmitate (C16:0), but not monounsaturated oleate (C18:1), have been demonstrated to induce apoptosis in a number of cell types, including the cardiomyocyte element of the heart (1-3). Cardiac myocyte apoptosis is an important contributor to myocardial dysfunction and heart failure due to a systematic reduction in the number of cardiomyocytes (4). Abnormally high blood fatty acid levels in patients result in acute myocardial infarction and increase the extent and severity of myocardial injury (5-7). In vitro studies have indicated that palmitate-induced cell apoptosis in cardiomyocytes is associated with the mitochondria-dependent apoptotic pathway, including cytochrome $\mathrm{c}$ release, loss of the mitochondrial membrane potential and consequent caspase-3 activation $(8,9)$.

A number of studies have hypothesized that increasing reactive oxygen species (ROS) production in cardiac cells and accompanying oxidative stress are major initiators of cardiovascular injury $(10,11)$. The tumor suppressor protein, p53, activates transcription of proapoptotic genes in several cell types prior to the onset of apoptosis $(12,13)$. The ratio of pro- and antiapoptotic Bcl-2 family members is crucial for cell apoptosis in response to lipotoxicity. p53 has been identified to regulate Bcl-2 family genes, leading to initiation of apoptosis (14). In addition, p53-transactivated genes have been revealed to increase ROS and general oxidative damage to all mitochondrial components, which disrupts mitochondrial oxidative phosphorylation, thereby contributing to ischemia/reperfusion injury (15-17). The extracellular signal-regulated kinase 1/2 (ERK1/2) signaling pathway is important for cell proliferation, growth and cell death (18). Previous studies have demonstrated that activation of the ERK1/2 signaling pathway is involved in the apoptotic process $(19,20)$. More recently, the ROS-activated ERK1/2 signaling pathway was found to be an important regulatory mechanism responsible for chemical hypoxia-induced cardiomyocyte injury (21). In addition, it has also been reported that excessive levels of glucose and free fatty acids induce tissue-specific cellular damage via increasing $\operatorname{ROS}(8,22,23)$. However, the underlying molecular mechanisms associated with cell apoptosis induced by palmitate remain unclear in cardiomyocytes. 
The present study aimed to identify the mechanisms of lipotoxicity in $\mathrm{H} 9 \mathrm{c} 2$ cells and to test the hypothesis that ROS production and the ERK1/2 signaling pathway are critical for palmitate-induced apoptosis in $\mathrm{H} 9 \mathrm{c} 2$ cells.

\section{Materials and methods}

Chemicals and reagents. Fetal bovine serum (FBS), Dulbecco's modified Eagle's medium (DMEM) and penicillin/streptomycin were obtained from Hyclone Laboratories, Inc. (Logan, UT, USA). Antibodies against p-Akt, total-Akt, caspase-3, Bcl-2, Bax and poly (ADP-ribose) polymerase (PARP) and horseradish peroxidase (HRP)-conjugated anti-rabbit or anti-mouse secondary antibodies were obtained from Cell Signaling Technology, Inc. (Danvers, MA, USA). Antibodies against p-ERK1/2, total ERK1/2, p53 and $\beta$-actin were purchased from Millipore (Billerica, MA, USA). Enhanced chemiluminescence (ECL) reagent was purchased from Millipore. Palmitate and bovine serum albumin (BSA) were obtained from Sigma-Aldrich (St. Louis, MO, USA). Stock solutions of $5 \mathrm{mM}$ PA/10\% BSA were prepared as previously described (24) and stored at $-20^{\circ} \mathrm{C}$. Stock solutions were heated for $15 \mathrm{~min}$ at $55^{\circ} \mathrm{C}$ and then cooled to room temperature prior to use.

Cell culture. H9c2 cells (a subclone of an original clonal cell line derived from embryonic BD1X rat heart tissue exhibiting a number of skeletal muscle properties) were obtained from the Cell Bank of Type Culture Collection of Chinese Academy of Sciences (Shanghai, China) and grown in DMEM supplemented with $10 \% \mathrm{FBS}$ and $1 \%$ penicillin/streptomycin in a humidified atmosphere of $95 \%$ air and $5 \% \mathrm{CO}_{2}$ at $37^{\circ} \mathrm{C}$. When cells reached $\sim 80 \%$ confluence, various doses of palmitate were added to the complete medium and incubated for $12 \mathrm{~h}$.

Evaluation of cell apoptosis by Hoechst 33342 staining. Cells were plated in 6-well chamber slides and allowed to adhere. Following $12 \mathrm{~h}$ of treatment, cells from each group were washed with phosphate-buffered saline (PBS) and fixed with $4 \%$ formalin for $10 \mathrm{~min}$. Hoechst $33342(10 \mu \mathrm{g} / \mathrm{ml})$ was applied for $30 \mathrm{~min}$ under dark conditions to stain the nuclei of the fixed cells. Slides were then washed with PBS and mounted in a mounting medium (PBS:glycerol, 1:1). Cells were examined and images were captured using a fluorescence microscope. Apoptotic cells were identified as those with a nucleus exhibiting brightly stained condensed chromatin or unclear fragments. Normal nuclei exhibited blue chromatin with an organized structure. For each experimental condition, four separate cell populations were prepared. Apoptotic indices were determined by direct visualization and counting of a minimum of 500 cells/population ( $\geq 100$ cells from five randomly selected fields). The apoptotic index was calculated using the following formula: (number of apoptotic cells/total cells counted) x 100 .

Assessment of cell viability by 3-(4,5-dimethylthiazol2-yl)-2,5-diphenyltetrazolium bromide (MTT) assay. Briefly, H9c2 cells were cultured in 96-well plates. Palmitate at concentrations of 0,100 or $150 \mu \mathrm{M}$ was added to the wells. Following treatment with palmitate for $12 \mathrm{~h}$, the culture medium was replaced with $200 \mu \mathrm{l}$ MTT solution $(5 \mathrm{mg} / \mathrm{ml}$ stock solution in PBS, diluted with culture medium to a final concentration of $0.5 \mathrm{mg} / \mathrm{ml}$ ). Following $4 \mathrm{~h}$ of incubation at $37^{\circ} \mathrm{C}$, the solution was removed and the produced formazan was solubilized in $150 \mu \mathrm{l}$ dimethyl sulfoxide. The absorbance was measured at $550 \mathrm{nM}$ using an automated microplate reader.

Measurement of intracellular ROS levels. Intracellular ROS levels were determined using a peroxide-sensitive fluorescent probe, 2',7'-dichlorofluorescein diacetate (DCFH-DA; Beyotime Institute of Biotechnology, Shanghai, China). DCFH-DA is converted by intracellular esterases to DCFH, which is oxidized into the highly fluorescent dichlorofluorescein in the presence of a specific oxidant. Cells were plated in 6-well chamber slides and allowed to adhere. Following $12 \mathrm{~h}$ of treatment, cells were loaded with $1 \mathrm{mM}$ DCFH-DA in DMEM in the dark for $30 \mathrm{~min}$ at $37^{\circ} \mathrm{C}$. Following incubation, cells were washed with PBS three times and mounted with a coverslip. Slides were immediately analyzed and images were captured on an Olympus Inverted Fuorescence microscope. For every well, six fields were randomly selected to photograph and integrated optical densities of the images were determined. Positive cells were treated with $6 \mathrm{mM}$ hydrogen peroxide for $1 \mathrm{~h}$ prior to addition of the fluorescent dye.

Western blot analysis. The cells were lysed in ice-cold RIPA buffer [50 mM Tris/ $\mathrm{HCl}$ (pH 7.4), $150 \mathrm{mM} \mathrm{NaCl}$, $1 \%$ NP-40, $0.5 \%$ deoxycholate and $0.1 \%$ sodium dodecyl sulfate (SDS)] and protease inhibitor phenylmethanesulfonyl fluoride (PMSF). The protein concentration of the samples was determined using the bicinchoninic acid (BSA) protein assay reagent kit (Pierce Biotechnology, Inc., Rockford, IL, USA) with BSA as the standard. For western blot analysis, $40 \mu \mathrm{g}$ protein was denatured by heating at $100^{\circ} \mathrm{C}$ for $10 \mathrm{~min}$ in SDS sample buffer, loaded onto and separated by 10 or $12 \%$ SDS polyacrylamide gels and then transferred to a polyvinylidene fluoride membrane. The membrane was blocked in 5\% (w/v) nonfat milk with $0.05 \%$ Tween-20 Tris-buffered saline buffer for $1 \mathrm{~h}$ and then incubated overnight at $4^{\circ} \mathrm{C}$ with the following primary antibodies: monoclonal anti-Akt $(1: 1,000)$, anti-p-Akt (1:1,000), anti-caspase-3 (1:1,000), anti-PARP (1:1,000), anti-p-ERK1/2 (1:500), anti-ERK1/2 (1:500), anti-Bcl-2 (1:1,000), anti-p53 (1:500) and anti-Bax (1:1,000). Anti- $\beta$-actin $(1: 1,500)$ was used to determine equal loading of the protein. Following this, membranes were incubated with HRP-conjugated anti-mouse or anti-rabbit secondary antibodies $(1: 3,000)$ for $1 \mathrm{~h}$ at $37^{\circ} \mathrm{C}$, washed and visualized for immunoreactivity using an ECL system. Optical density was determined using FluorChem FC2 and readings were normalized to a control sample and presented in an arbitrary densitometry unit.

Statistical analysis. Quantitative data are presented as the mean \pm SEM determined from at least three independent experiments. Statistical analysis was based on the Student's t-test for comparison of two groups or one-way analysis of variance for multiple comparisons. $\mathrm{P}<0.05$ was considered to indicate a statistically significant difference. 
A
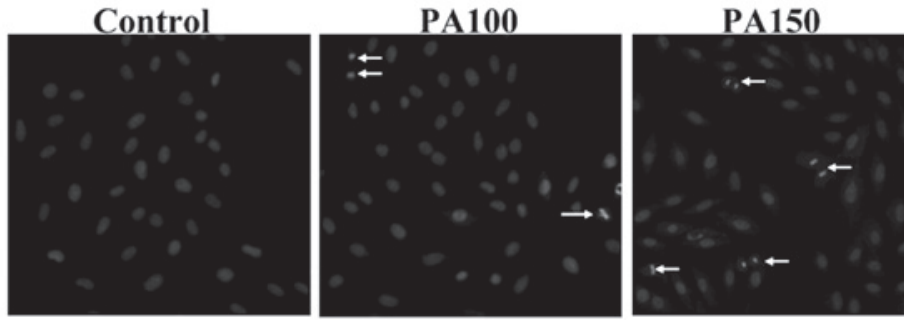

$\mathbf{B}$
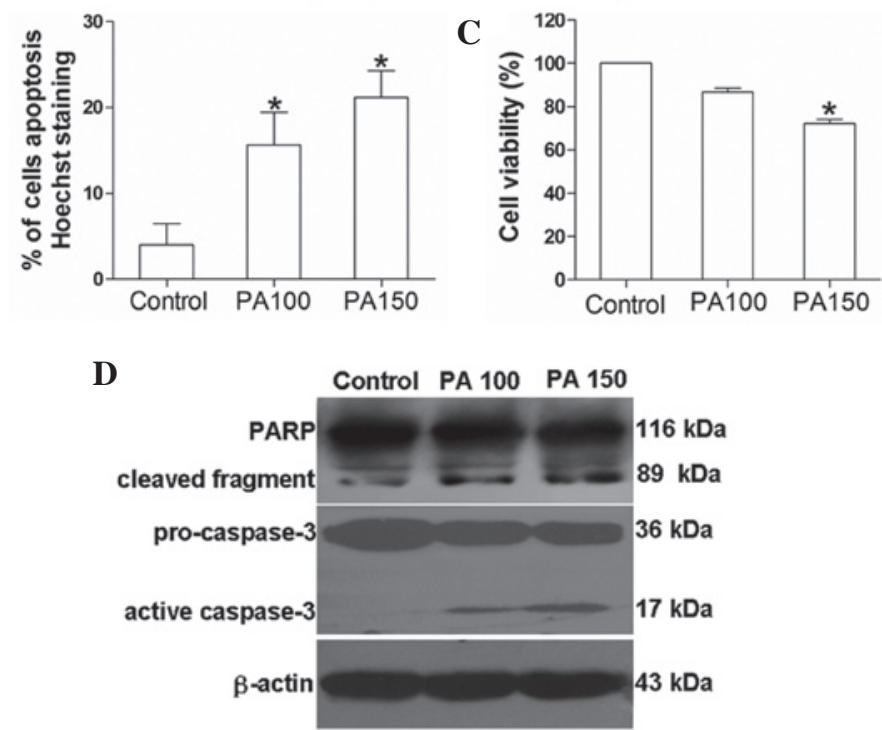

$\mathbf{E}$

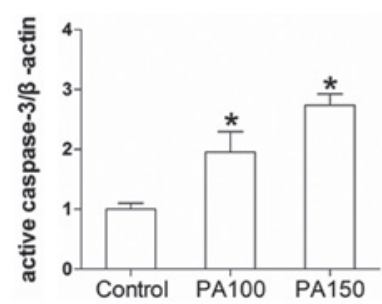

$\mathbf{F}$

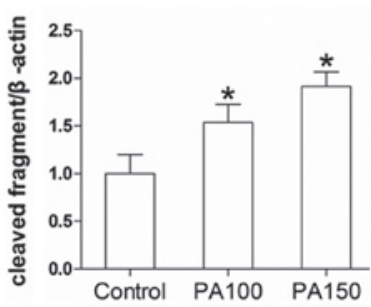

Figure 1. Palmitate-induced apoptosis of H9c2 cells. Cells were treated with palmitate (0, 100 and $150 \mu \mathrm{M})$ for $12 \mathrm{~h}$. (A and B) Cell apoptosis was determined by Hoechst 33342 staining and (C) cell viability was measured using the MTT assay. Levels of (D and E) active caspase-3 and (D and F) cleaved PARP were measured by western blot analysis. Results are reported as mean \pm SEM. ${ }^{*} \mathrm{P}<0.05$, vs. control. MTT, 3-(4,5-dimethylthiazol-2-yl)-2,5-diphenyltetrazolium bromide; PARP, poly (ADP-ribose) polymerase; PA, palmitate.

\section{Results}

Palmitate-induced apoptosis of $\mathrm{H} 9 \mathrm{c} 2$ cells. H9c2 cells were treated with various concentrations of palmitate $(0,100$ and $150 \mu \mathrm{M}$ ) for $12 \mathrm{~h}$. A marked increase in the number of apoptotic cells was observed in $\mathrm{H} 9 \mathrm{c} 2$ cells by Hoechst 33342 staining (Fig. 1A and B) and decreased cell viability was measured by the MTT assay (Fig. 1C). Western blot analysis results revealed that expression of active caspase-3 (Fig. 1D and E) and cleaved PARP (Fig. 1D and F), two well-established hallmarks of apoptosis, was increased following treatment with palmitate $(25,26)$. These results indicate that activation of caspase-3 and PARP is necessary for palmitate-induced apoptosis in $\mathrm{H} 9 \mathrm{c} 2$ cells.

ROS levels increased during palmitate treatment in $\mathrm{H} 9 \mathrm{c} 2 \mathrm{cells}$. Cellular ROS levels in $\mathrm{H} 9 \mathrm{c} 2$ cells treated with various concentrations of palmitate $(0,100$ and $150 \mu \mathrm{M})$ were examined. Following treatment with palmitate for $12 \mathrm{~h}$, intracellular ROS levels were measured using a DCFH-DA assay. Intracellular
ROS levels were identified to be significantly increased in $\mathrm{H} 9 \mathrm{c} 2$ cells when exposed to 100 and $150 \mu \mathrm{M}$ palmitate for $12 \mathrm{~h}$ compared with the control (Fig. 2). Intracellular ROS production was significantly deceased when exposed to $150 \mu \mathrm{M}$ palmitate combined with the ERK1/2 inhibitor, U0126, compared with exposure to $150 \mu \mathrm{M}$ palmitate alone (Fig. 2). These results indicate that palmitate induces H9c2 cell apoptosis and increases ROS generation simultaneously.

Effect of Bax, Bcl-2 and p53 protein expression during palmitate treatment in $\mathrm{H} 9 \mathrm{c} 2$ cells. To determine the correlation between palmitate-induced apoptosis and Bcl-2 family members, proapoptotic Bax and antiapoptotic $\mathrm{Bcl}-2$ protein expression in $\mathrm{H} 9 \mathrm{c} 2$ cells was determined by western blot analysis (Fig. 3A-C). Proapoptotic Bax expression was increased and antiapoptotic Bcl-2 levels were decreased by palmitate treatment. p53 protein expression was also found to be increased following palmitate-induced apoptosis in $\mathrm{H} 9 \mathrm{c} 2$ cells (Fig. 3A and D). Results indicate that Bax and Bcl-2 are involved in $\mathrm{H} 9 \mathrm{c} 2$ cell apoptosis via palmitate induction. In 


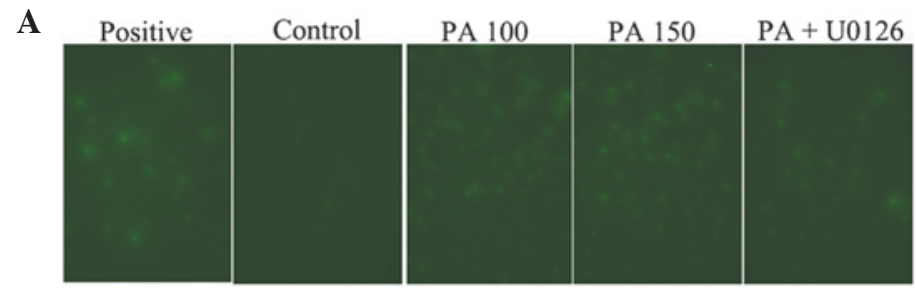

$\mathbf{B}$

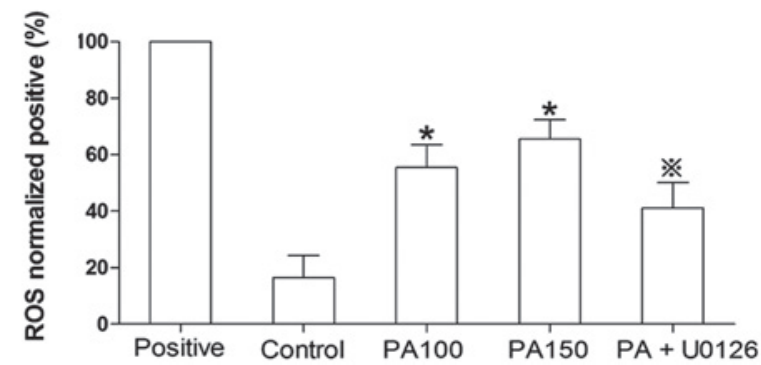

Figure 2. Effect of ROS generation during palmitate treatment in H9c2 cells. Cells were exposed to palmitate $(0,100$ and $150 \mu \mathrm{M})$ or $150 \mu \mathrm{M}$ palmitate combined with ERK1/2 inhibitor, U0126, for $12 \mathrm{~h}$. Intracellular ROS was determined using DCFH-DA. Results are presented as mean \pm SEM. "P<0.05, vs. control and ${ }^{*} \mathrm{P}<0.05$, vs. $150 \mu \mathrm{M}$ palmitate. ROS, reactive oxygen species; ERK1/2, extracellular signal-regulated kinase 1/2; DCFH-DA, 2',7'-dichlorofluorescein diacetate; PA, palmitate.
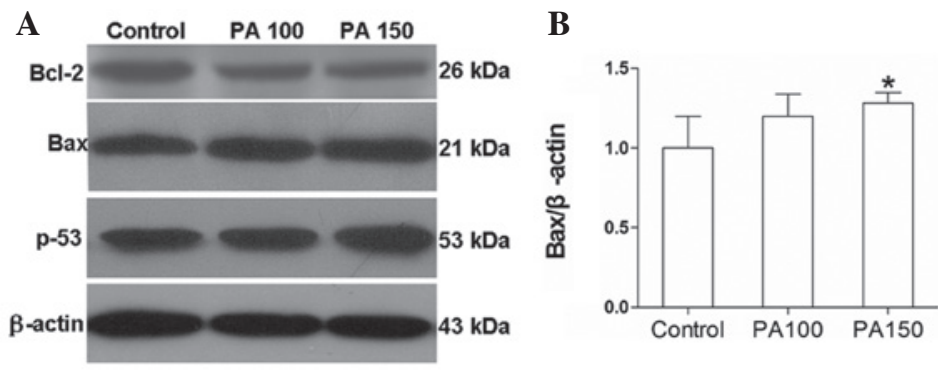

C
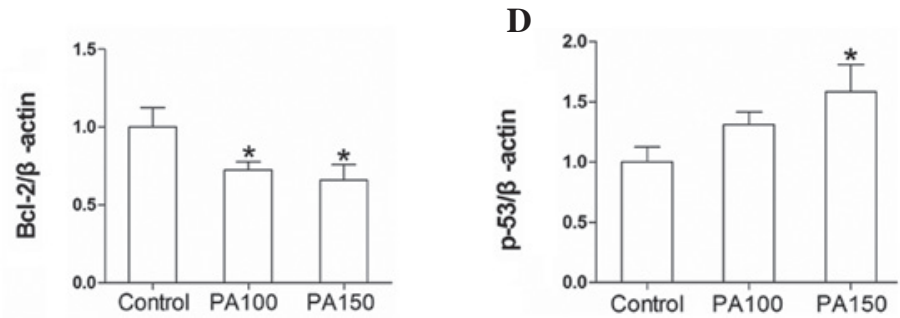

Figure 3. Effect of palmitate on Bax, Bcl-2 and p53 protein expression in $\mathrm{H} 9 \mathrm{c} 2$ cells. Cells were incubated with palmitate $(0,100$ and $150 \mu \mathrm{M})$ for $12 \mathrm{~h}$. Protein levels of (A and B) proapoptotic Bax, (A and C) antiapoptotic Bcl-2 and (A and D) p53 were measured by western blot analysis. Results are reported as mean \pm SEM. ${ }^{*} \mathrm{P}<0.05$, vs. control. PA, palmitate.

addition, p53 was also involved in palmitate-induced apoptosis in $\mathrm{H} 9 \mathrm{c} 2$ cells.

ERK1/2 and Akt signaling pathways were involved in palmitate-induced apoptosis of $\mathrm{H} 9 \mathrm{c} 2$ cells. To investigate the apoptosis-related signaling pathways that are activated in $\mathrm{H} 9 \mathrm{c} 2$ cells treated with palmitate for $12 \mathrm{~h}$, levels of $\mathrm{p}-\mathrm{ERK} 1 / 2$ and p-Akt were examined using western blot analayis following $\mathrm{H} 9 \mathrm{c} 2$ cell exposure to various concentrations of palmitate $(0,100$ and $150 \mu \mathrm{M})$. Levels of p-ERK1/2 were found to be significantly increased (Fig. 4A and B) and p-Akt was markedly decreased (Fig. 4A and C) following H9c2 cell treatment with palmitate. These observations demonstrate that the ERK1/2 and Akt signaling pathways were involved in palmitate-induced apoptosis in H9c2 cells. To further determine the role of ERK1/2 in palmitate-induced apoptosis of $\mathrm{H} 9 \mathrm{c} 2$ cells, the ERK1/2 inhibitor, U0126 (10 $\mu \mathrm{M})$, was used, as described previously (27). Levels of active caspase-3 and cleaved PARP were found to decrease significantly when treated with $\mathrm{U} 0126$ in the presence of $150 \mu \mathrm{M}$ palmitate (Fig. 4D-F). Levels of ROS production were observed to be decreased significantly compared with $150 \mu \mathrm{M}$ palmitate alone (Fig. 2). The results demonstrate that the ERK1/2 signaling pathway is involved in palmitate-induced apoptosis in $\mathrm{H} 9 \mathrm{c} 2$ cells.

\section{Discussion}

Cardiac myocyte apoptosis is an important contributor to myocardial dysfunction and heart failure and serum fatty acid levels, including palmitate, have been observed at elevated levels in patients with acute myocardial infarction $(4,6)$. A 


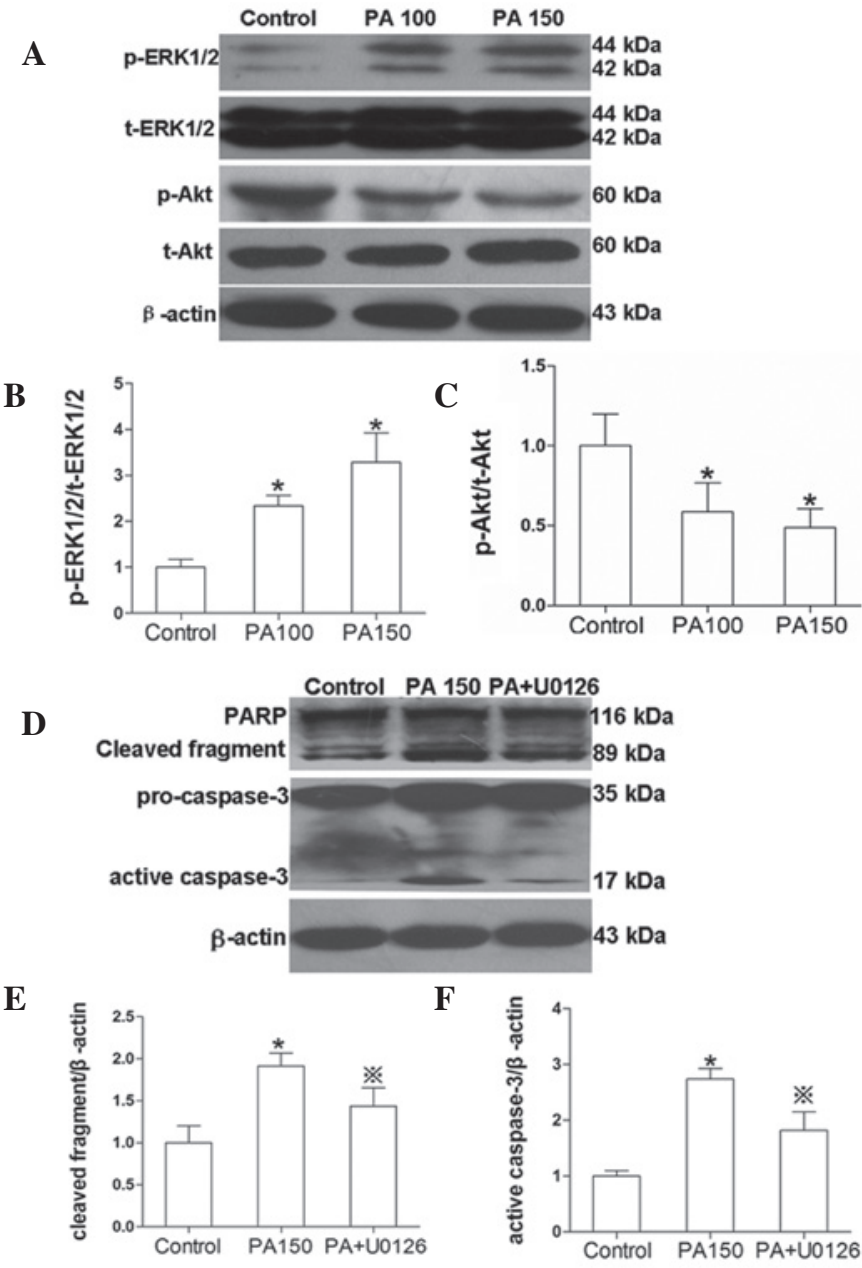

Figure 4. ERK1/2 and Akt signaling pathways are involved in palmitate-induced apoptosis in H9c2 cells. Cells were exposed to palmitate $(0,100$ and $150 \mu \mathrm{M})$ or $150 \mu \mathrm{M}$ palmitate combined the ERK1/2 inhibitor, U0126, for $12 \mathrm{~h}$. Protein levels of (A and B) p-ERK1/2, (A and C) p-Akt, (D and E) cleaved PARP and ( $\mathrm{D}$ and $\mathrm{F}$ ) active caspase- 3 were measured by western blot analysis. Results are presented as mean $\pm \mathrm{SEM}$. ${ }^{*} \mathrm{P}<0.05$, vs. control and ${ }^{*} \mathrm{P}<0.05$, vs. $150 \mu \mathrm{M}$ palmitate. ERK1/2, extracellular signal-regulated kinase 1/2; PARP, poly (ADP-ribose) polymerase; PA, palmitate.

number of studies have reported that increased levels of ROS production are a contributing factor to apoptosis in cardiac myocytes (28-31). In the current study, ROS production was identified at increased levels following palmitate-induced apoptosis in $\mathrm{H} 9 \mathrm{c} 2$ cells, consistent with previous studies $(2,32)$. Increasing ROS production has been demonstrated to account for apoptosis in response to palmitate in numerous cell lines, including neutrophils and fibroblasts and endothelial, pancreatic $\beta$ and hepatic cells (33-36). In addition, the results of the present study indicate that increased levels of ROS production may be one of the mechanisms by which palmitate induces apoptosis in $\mathrm{H} 9 \mathrm{c} 2$ cells. By contrast, this observation is inconsistent with a previous study that demonstrated that palmitate-induced apoptosis in neonatal rat cardiomyocytes was not dependent on increased ROS production levels (37). The cause of this discrepancy is currently unknown. Nevertheless, present results support the hypothesis that increased ROS production promotes apoptosis in palmitate-induced in $\mathrm{H} 9 \mathrm{c} 2$ cells.

The ratio of pro- and antiapoptotic Bcl-2 family members is crucial for cell apoptosis in response to lipotoxicity. The antiapoptotic protein $\mathrm{Bcl}-2$ is considered an important cellular component and prevents cell apoptosis. Proapoptotic Bax promotes apoptosis. Previous studies have indicated that apoptosis is associated with upregulation of proapoptotic Bax and downregulation of antiapoptotic Bcl-2 (38,39). The results of the present study also demonstrated that levels of $\mathrm{Bcl}-2$ were attenuated and Bax were increased in response to palmitate-induced apoptosis in H9c2 cells. These changes in levels of Bcl-2 family members may have a direct effect on mitochondrial membrane pore formation and consequent activation of caspase- 3 and PARP activity, therefore leading to activation of the intrinsic apoptotic pathway. The tumor suppressor protein p53 is a transcription factor with a short half-life and is present at low levels in normal cells. p53 is known to activate transcription of proapoptotic genes in specific cell types prior to the onset of apoptosis $(12,13)$. Bcl-2 family members may be directly transactivated by p53, which is a sensor of cellular stress, by transcriptionally regulating these genes to initiate intrinsic apoptosis (14). Previous studies have also demonstrated that p53 transactivates genes responsible for increased ROS production and general oxidative damage to all mitochondrial components. These events disrupt mitochondrial oxidative phosphorylation, thereby contributing to a number of human diseases, including ischemia/reperfusion injury (15-17). In the present study, results indicate that 
increased p53 levels were accompanied by increasing levels of ROS production, reducing the ratio of $\mathrm{Bcl}-2 / \mathrm{Bax}$ and resulting in palmitate-induced apoptosis in $\mathrm{H} 9 \mathrm{c} 2$ cells. However, the mechanism by which palmitate induces apoptosis of H9c2 cells requires additional studies.

ERK1/2/mitogen-activated protein kinase is a well-known signal transduction cascade involved in the response to extracellular stimuli and is important for cell proliferation, growth and cell death $(18,29)$. However, the mechanism by which the ERK1/2 signaling pathway is activated in apoptosis remains controversial. Previous studies have indicated that activation of the ERK1/2 signaling pathway mediates cell proliferation and survival $(40,41)$. In addition, sustained activation of the ERK1/2 pathway has been associated with the apoptotic process $(19,20,31)$. A recent study indicated that the ROS-activated ERK1/2 signaling pathway is an important regulatory mechanism responsible for chemical hypoxia-induced cardiomyocyte injury (21). In the present study, apoptosis induced by palmitate simultaneously increased ROS production and levels of p-ERK1/2 in H9c2 cells. The ERK1/2 inhibitor, U0126, decreased ROS production and attenuated palmitate-induced apoptosis in $\mathrm{H} 9 \mathrm{c} 2$ cells through decreasing the activity of caspase- 3 and PARP. In addition, the PI3K/Akt signaling pathway has been identified to play a major role in the prevention of apoptosis (42). Acute activation of this signaling pathway has been demonstrated to promote cardiomyocyte survival and function in vitro and in vivo (43). Current results indicate that p-Akt levels were decreased following palmitate-induced apoptosis in $\mathrm{H} 9 \mathrm{c} 2$ cells.

The results of the present study indicate that palmitate induced apoptosis in $\mathrm{H} 9 \mathrm{c} 2$ cells through activation of the ERK1/2 signaling pathway and increasing levels of intracellular ROS generation, resulting in activation of caspase-3 and PARP activity. These results are likely to provide insight into the mechanisms by which ROS mediate oxidative stress in response to palmitate, leading to lipotoxicity cardiomyopathy.

\section{Acknowledgements}

The current study was supported by the National Clinical Key Specialty Construction Projects and National Natural Science Foundation of China (no. 81100959).

\section{References}

1. de Vries JE, Vork MM, Roemen TH, et al: Saturated but not mono-unsaturated fatty acids induce apoptotic cell death in neonatal rat ventricular myocytes. J Lipid Res 38: 1384-1394, 1997.

2. Miller TA, LeBrasseur NK, Cote GM, et al: Oleate prevents palmitate-induced cytotoxic stress in cardiac myocytes. Biochem Biophys Res Commun 336: 309-315, 2005.

3. Hickson-Bick DL, Buja LM and McMillin JB: Palmitatemediated alterations in the fatty acid metabolism of rat neonatal cardiac myocytes. J Mol Cell Cardiol 32: 511-519, 2000

4. Haunstetter A and Izumo S: Apoptosis: basic mechanisms and implications for cardiovascular disease. Circ Res 82: 1111-1129, 1998.

5. Opie LH: Metabolism of free fatty acids, glucose and catecholamines in acute myocardial infarction. Relation to myocardial ischemia and infarct size. Am J Cardiol 36: 938-953, 1975.

6. Oliver MF, Kurien VA and Greenwood TW: Relation between serum-free-fatty acids and arrhythmias and death after acute myocardial infarction. Lancet 1: 710-714, 1968.
7. Vik-Mo $\mathrm{H}$ and Mjos OD: Influence of free fatty acids on myocardial oxygen consumption and ischemic injury. Am J Cardiol 48: 361-365, 1981.

8. Listenberger LL, Ory DS and Schaffer JE: Palmitate-induced apoptosis can occur through a ceramide-independent pathway. J Biol Chem 276: 14890-14895, 2001.

9. Sparagna GC, Hickson-Bick DL, Buja LM and McMillin JB: A metabolic role for mitochondria in palmitate-induced cardiac myocyte apoptosis. Am J Physiol Heart Circ Physiol 279: H2124-H2132, 2000.

10. Cave AC, Brewer AC, Narayanapanicker A, et al: NADPH oxidases in cardiovascular health and disease. Antioxid Redox Signal 8: 691-728, 2006.

11. Selvaraju V, Joshi M, Suresh S, Sanchez JA, Maulik N and Maulik G: Diabetes, oxidative stress, molecular mechanism and cardiovascular disease - an overview. Toxicol Mech Methods 22: 330-335, 2012.

12. Polyak K, Xia Y, Zweier JL, Kinzler KW and Vogelstein B: A model for p53-induced apoptosis. Nature 389: 300-305, 1997.

13. Agarwal ML, Taylor WR, Chernov MV, Chernova OB and Stark GR: The p53 network. J Biol Chem 273: 1-4, 1998.

14. Hemann MT and Lowe SW: The p53-Bcl-2 connection. Cell Death Differ 13: 1256-1259, 2006.

15. Haupt S, Berger M, Goldberg Z and Haupt Y: Apoptosis - the p53 network. J Cell Sci 116: 4077-4085, 2003

16. von Harsdorf R, Li PF and Dietz R: Signaling pathways in reactive oxygen species-induced cardiomyocyte apoptosis. Circulation 99: 2934-2941, 1999.

17. Circu ML and Aw TY: Reactive oxygen species, cellular redox systems and apoptosis. Free Radic Biol Med 48: 749-762, 2010.

18. $\mathrm{Lu} \mathrm{Z}$ and Xu S: ERK1/2 MAP kinases in cell survival and apoptosis. IUBMB Life 58: 621-631, 2006.

19. Tantini B, Pignatti C, Fattori M, et al: Polyamine depletion inhibits etoposide-induced NF-kappaB activation in transformed mouse fibroblasts. Amino Acids 27: 207-214, 2004.

20. Liu J, Mao W, Ding B and Liang CS: ERKs/p53 signal transduction pathway is involved in doxorubicin-induced apoptosis in H9c2 cells and cardiomyocytes. Am J Physiol Heart Circ Physiol 295: H1956-H1965, 2008.

21. Dong XB, Yang CT, Zheng DD, et al: Inhibition of ROS-activated ERK1/2 pathway contributes to the protection of H2S against chemical hypoxia-induced injury in $\mathrm{H} 9 \mathrm{c} 2$ cells. Mol Cell Biochem 362: 149-157, 2012.

22. Dyntar D, Eppenberger-Eberhardt M, Maedler K, et al: Glucose and palmitic acid induce degeneration of myofibrils and modulate apoptosis in rat adult cardiomyocytes. Diabetes 50: 2105-2113, 2001.

23. Fiordaliso F, Leri A, Cesselli D, et al: Hyperglycemia activates p53 and p53-regulated genes leading to myocyte cell death. Diabetes 50: 2363-2375, 2001.

24. Cousin SP, Hugl SR, Wrede CE, Kajio H, Myers MG Jr and Rhodes CJ: Free fatty acid-induced inhibition of glucose and insulin-like growth factor I-induced deoxyribonucleic acid synthesis in the pancreatic beta-cell line INS-1. Endocrinology 142: 229-240, 2001.

25. Nicholson DW and Thornberry NA: Caspases: killer proteases. Trends Biochem Sci 22: 299-306, 1997.

26. Herceg Z and Wang ZQ: Failure of poly(ADP-ribose) polymerase cleavage by caspases leads to induction of necrosis and enhanced apoptosis. Mol Cell Biol 19: 5124-5133, 1999.

27. Diffley JM, Wu M, Sohn M, Song W, Hammad SM and Lyons TJ: Apoptosis induction by oxidized glycated LDL in human retinal capillary pericytes is independent of activation of MAPK signaling pathways. Mol Vis 15: 135-145, 2009.

28. Takano H, Zou Y, Hasegawa H, Akazawa H, Nagai $T$ and Komuro I: Oxidative stress-induced signal transduction pathways in cardiac myocytes: involvement of ROS in heart diseases. Antioxid Redox Signal 5: 789-794, 2003.

29. Yao Y, Li R, Ma Y, et al: $\alpha$-Lipoic acid increases tolerance of cardiomyoblasts to glucose/glucose oxidase-induced injury via ROS-dependent ERK1/2 activation. Biochim Biophys Acta 1823: 920-929, 2012.

30. Tsai KH, Wang WJ, Lin CW, et al: NADPH oxidase-derived superoxide anion-induced apoptosis is mediated via the JNK-dependent activation of NF- $\mathrm{KB}$ in cardiomyocytes exposed to high glucose. J Cell Physiol 227: 1347-1357, 2012.

31. Sun B, Sun GB, Xiao J, et al: Isorhamnetin inhibits HO-induced activation of the intrinsic apoptotic pathway in $\mathrm{H} 9 \mathrm{c} 2$ cardiomyocytes through scavenging reactive oxygen species and ERK inactivation. J Cell Biochem 113: 473-485, 2012. 
32. Zhu H, Yang Y, Wang Y, Li J, Schiller PW and Peng T: MicroRNA-195 promotes palmitate-induced apoptosis in cardiomyocytes by down-regulating Sirt1. Cardiovasc Res 92: 75-84, 2011.

33. Nakamura S, Takamura T, Matsuzawa-Nagata N, et al: Palmitate induces insulin resistance in H4IIEC3 hepatocytes through reactive oxygen species produced by mitochondria. J Biol Chem 284: 14809-14818, 2009.

34. Maloney E, Sweet IR, Hockenbery DM, et al: Activation of NF-kappaB by palmitate in endothelial cells: a key role for NADPH oxidase-derived superoxide in response to TLR4 activation. Arterioscler Thromb Vasc Biol 29: 1370-1375, 2009.

35. Lin N, Chen H,Zhang H, Wan X and Su Q: Mitochondrial reactive oxygen species (ROS) inhibition ameliorates palmitate-induced INS-1 beta cell death. Endocrine 42: 107-117, 2012.

36. Yeop Han C, Kargi AY, Omer M, et al: Differential effect of saturated and unsaturated free fatty acids on the generation of monocyte adhesion and chemotactic factors by adipocytes: dissociation of adipocyte hypertrophy from inflammation. Diabetes 59: 386-396, 2010.

37. Hickson-Bick DL, Sparagna GC, Buja LM and McMillin JB Palmitate-induced apoptosis in neonatal cardiomyocytes is not dependent on the generation of ROS. Am J Physiol Heart Circ Physiol 282: H656-H664, 2002.
38. Shimabukuro M, Wang MY, Zhou YT, Newgard CB and Unger RH: Protection against lipoapoptosis of beta cells through leptin-dependent maintenance of Bcl-2 expression. Proc Natl Acad Sci USA 95: 9558-9561, 1998.

39. Peterson JM, Wang Y, Bryner RW, Williamson DL and Alway SE: Bax signaling regulates palmitate-mediated apoptosis in C(2)C(12) myotubes. Am J Physiol Endocrinol Metab 295: E1307-E1314, 2008.

40. Cheng M, Sexl V, Sherr CJ and Roussel MF: Assembly of cyclin D-dependent kinase and titration of p27Kip1 regulated by mitogen-activated protein kinase kinase (MEK1). Proc Natl Acad Sci USA 95: 1091-1096, 1998.

41. Tran SE, Holmstrom TH, Ahonen M, Kahari VM and Eriksson JE: MAPK/ERK overrides the apoptotic signaling from Fas, TNF and TRAIL receptors. J Biol Chem 276: 16484-16490, 2001.

42. Martelli AM, Faenza I, Billi AM, et al: Intranuclear 3'-phosphoinositide metabolism and Akt signaling: new mechanisms for tumorigenesis and protection against apoptosis? Cell Signal 18: 1101-1107, 2006.

43. Matsui $\mathrm{T}$ and Rosenzweig A: Convergent signal transduction pathways controlling cardiomyocyte survival and function: the role of PI 3-kinase and Akt. J Mol Cell Cardiol 38: 63-71, 2005. 